\title{
Avaliação da reatividade ao ataque químico de resíduo oriundo da mineração da scheelita utilizado como agregado em argamassas cimentícias
}

\author{
Evaluation of reactivity to the chemical attack of waste from the \\ mining of scheelite used as aggregate in cementitious mortars \\ Maria de Lourdes Xavier de França Neta' ${ }^{\oplus}$, Sâmea Valensca Alves Barros ${ }^{1} \oplus$, \\ Gerbeson Carlos Batista Dantas ${ }^{1 *}{ }^{(0)}$, Stefeson Bezerra de Melo' ${ }^{1}$, \\ Gelmires de Araújo Neves ${ }^{2} \odot$, Valteson da Silva Santos ${ }^{3} \oplus$, Walney Gomes da Silva ${ }^{3} \oplus$
}

\begin{abstract}
RESUMO
A mineração de scheelita, localizada em Currais Novos, Rio Grande do Norte, tem gerado grandes volumes de resíduos sólidos que são destinados inadequadamente aos sistemas ambientais, causando impactos ambientais negativos ao município. Uma das alternativas encontradas para destinar adequadamente esses resíduos é o uso em argamassas de matriz cimentícia. No entanto, não há estudos consistentes sobre a viabilidade técnica quanto aos ataques químicos e à influência na sua durabilidade. Nesse contexto, este trabalho teve como objetivo verificar se as argamassas confeccionadas com resíduos da mineração de scheelita em substituição total ao agregado convencional são suscetíveis ao ataque por sulfato de sódio. A caracterização física, química e mineralógica do resíduo foi realizada fazendo uso das seguintes técnicas: análise granulométrica por peneiramento; determinação da massa unitária; obtenção do teor de material pulverulento; espectrometria de fluorescência de raios X, e difração de raios X. A investigação da ocorrência do ataque por sulfato de sódio foi avaliada pela variação dimensional dos corpos de prova quando imersos em solução de sulfato de sódio, de acordo com a metodologia da Associação Brasileira de Normas Técnicas NBR 13583. Os resultados do traço 1:3 indicaram que os agregados oriundos dos resíduos da mineração de scheelita apresentaram comportamento reativo ao ataque por sulfato de sódio (expansão maior que 0,06\%), bem como houve aumento da resistência à compressão simples em 4,74\%. Portanto, embora tenha sido constatado que os corpos de prova incorporados com resíduos de scheelita tenham sido reativos ao sulfato, observou-se que não foram capazes de deteriorar mecanicamente os corpos de prova.
\end{abstract}

Palavras-chave: agregados alternativos; ataque químico por sulfato de sódio; resíduos de mineração.

\begin{abstract}
The scheelite mining, located in Currais Novos, Rio Grande do Norte, has generated large volumes of solid waste that are inadequately destined for environmental systems, causing negative environmental impacts to the municipality. One of the alternatives to destination of these residues is the use in cementitious matrix mortars. However, there are no consistent studies on the technical feasibility of chemical attacks and influence on their durability. In this context, this work aimed to verify whether mortars made with scheelite mining residues in total substitution to conventional aggregate are susceptible to attack by sodium sulfate. The physical, chemical, and mineralogical characterization of the residue was carried out using the following techniques: sieve particle size analysis; determination of unit mass; obtaining the content of powdery material; X-ray fluorescence spectrometry, and X-ray diffraction. In the investigation of the occurrence of sodium sulfate attack was evaluated by the dimensional variation of the specimens when immersed in sodium sulfate solution, according to the methodology of Associação Brasileira de Normas Técnicas NBR 13583. The results of mixture 1:3 indicated that the aggregates from scheelite mining residues showed a reactive behavior to attack by sodium sulfate (expansion greater than $0.06 \%$ ), as well as an increase in resistance to simple compression by $4.74 \%$. Therefore, although it was found that specimens incorporated with scheelite residues were reactive to sulfate, it was observed that they were not able to mechanically deteriorate the specimens.
\end{abstract}

Keywords: alternative aggregates; chemical attack by sodium sulfate: mining residues.

$\square$

'Universidade Federal Rural do Semi-Árido - Mossoró (RN), Brasil.

ZUniversidade Federal de Campina Grande - Campina Grande (PA), Brasil.

${ }^{3}$ Instituto Federal do Rio Grande do Norte - Natal (RN), Brasil.

*Autor correspondente: gerbeson_dantas@hotmail.com

Conflitos de interesse: os autores declaram não haver conflitos de interesse.

Financiamento: nenhum.

Recebido: 30/01/202O - Aceito: 21/12/2020 - Reg. ABES: 20200183 


\section{INTRODUÇÃO}

A mineração de scheelita no município de Currais Novos, Rio Grande do Norte, continua tendo grande importância para o cenário brasileiro, sendo a principal região do país responsável pela extração do minério para exportação (em 2016), exportou cerca de US\$ 2 milhões em scheelita, de acordo com dados obtidos pela Secretaria de Estado do Desenvolvimento Econômico do Rio Grande do Norte - SEDEC/RN (RIO GRANDE DO NORTE, 2016). No cenário mundial, a China é o principal produtor e consumidor global desse minério. Como são poucos países no mundo que comercializam esse minério, destaca-se a importância da extração na região do Seridó do Rio Grande do Norte. Nessa perspectiva, a produção do minério para exportação tem gerado um impasse ambiental, tanto pelo grande volume de resíduos que cobrem uma área de $121.500 \mathrm{~m}^{2}$, totalizando 3.110 .400 toneladas de resíduos, quanto por sua destinação final ambientalmente inadequada (PETTA et al., 2014; MOREIRA et al., 2008; ERCIKDI et al., 2015).

Esses resíduos são materiais de origem mineral, não biodegradáveis e que, quando destinados inadequadamente no meio ambiente, provocam degradação dos sistemas naturais, contaminando a água e o solo (RIBEIRO et al., 2007; MERSONI \& REICHERT, 2017; PIMENTEL et al., 2018). Ainda que segundo a classificação da Associação Brasileira de Normas Técnicas (ABNT) NBR 10.004 os resíduos da exploração de scheelita sejam classificados como resíduos de Classe II B - Inertes - (ABNT, 2004), é possível que haja contaminantes em sua constituição química dependendo das condições de formação do jazimento e que, associado ao gerenciamento inadequado desses resíduos, podem desencadear danos ambientais significativos. Logo, torna-se relevante efetivar as políticas de controle e remediação ambiental previstas na estrutura legal brasileira.

Nessa perspectiva, insere-se a Política Nacional de Resíduos Sólidos (Lei Federal $n^{\circ}$ 12.305/2010). A referida lei traz uma série de exigências que devem ser tomadas pelas empresas geradoras envolvidas em todo ciclo de geração dos resíduos. Essas exigências devem estar em seu plano de gerenciamento de resíduos sólidos oriundos de sua atividade, e nesse contexto também se insere a atividade mineradora. Entretanto, ainda que haja avanços gradativos, o Brasil ainda apresenta dificuldade em efetivar plenamente essa exigência (DANTAS et al., 2017).

Uma das saídas para a destinação final ambientalmente adequada dos resíduos de scheelita é sua utilização na indústria da construção civil, mais especificamente como substituinte total dos agregados das argamassas e dos concretos. Entretanto, é necessário que haja viabilidade técnica dessa utilização. Costa Filho (2017), Medeiros (2016), Alves et al., (2016) e Paiva (2013) estudaram a substituição do agregado miúdo pelo agregado oriundo do resíduo da mineração de scheelita na confecção de concreto e argamassas, comprovando sua viabilidade técnica quanto à resistência mecânica. Medeiros (2016) investigou vários teores de substituição $(0,25,50,75$ e 100\%) para os traços 1:1:6 e 1:3, verificando que a substituição total (100\%) foi a que obteve o melhor desempenho quanto à resistência à compressão simples aos 28 dias, alcançando um valor de 9,82 Mpa. No entanto, não houve estudos que avaliassem sua viabilidade técnica quanto à durabilidade desses materiais, sobretudo com enfoque nos ataques químicos por sulfatos.

Os ataques químicos por sulfatos são um dos que mais afetam a durabilidade dos materiais de matrizes cimentícias. Os íons sulfatos $\left(\mathrm{SO}_{4}^{2-}\right)$ reagem com a portlandita $\left(\mathrm{Ca}(\mathrm{OH})_{2}\right)$, o silicato de cálcio hidratado $\left(3 \mathrm{CaO} \cdot 2 \mathrm{SiO}_{2} 3 \mathrm{H}_{2} \mathrm{O}\right)$ e o monossulfoaluminato de cálcio hidratado $\left(\mathrm{C}_{3} \mathrm{~A} . \mathrm{CaSO} 4.14 \mathrm{H} 2 \mathrm{O}\right)$ presentes no cimento Portland utilizado na argamassa, formando gipsita $\left(\mathrm{CaSO}_{4} \cdot 2 \mathrm{H}_{2} \mathrm{O}\right)$, etringita secundária $\left(\mathrm{C}_{3} \mathrm{~A} \cdot 3 \mathrm{CaSO}_{4} \cdot 33 \mathrm{H}_{2} \mathrm{O}\right)$ e, em alguns casos, taumasita $\left(\mathrm{CaSiO}_{3} \cdot \mathrm{CaCO}_{3} \cdot \mathrm{CaSO}_{4} \cdot 15 \mathrm{H}_{2} \mathrm{O}\right.$ ) (HOPPE FILHO, et al., 2015; OUYANG, et al., 2014). Esses compostos alteram a estrutura porosa das argamassas em razão da pressão da cristalização dos sais formados, causando expansão ou contração volumétrica da estrutura, o que pode causar fissuras e degradação mecânica (ROZIÈRE, et al., 2009; MEHTA, et al., 2008; BARROS et al., 2019). Logo, é crucial estudar a reatividade dos agregados oriundos de resíduos da mineração de scheelita em relação aos sulfatos para que se possa fazer uso em argamassas para emprego na construção civil.

Nesse contexto, considerando que não há estudos que investiguem a durabilidade de argamassas preparadas com scheelita quando atacadas por sulfatos e visando oferecer uma destinação final ambientalmente adequada a esses resíduos, este trabalho teve como objetivo verificar se as argamassas confeccionadas com resíduo da mineração de scheelita em substituição total ao agregado convencional são suscetíveis ao ataque por sulfato de sódio.

\section{METODOLOGIA}

\section{Materiais}

Os materiais convencionais utilizados neste trabalho foram:

- Cimento Portland CP V ARI MAX (Nacional, Cimento Portland Sociedade Brasileira): por não conter pozolana em sua composição química (Tabela 1), de acordo com a NBR 5737 (ABNT, 1992), é adequado para esta investigação, uma vez que não há influência da adição de minerais, com exceção do teor de material carbonáceo permitido pela norma.

- Cal hidratada CH-I proveniente das Indústrias Carbomil, localizada em Limoeiro do Norte, Ceará: escolhida por apresentar elevado teor de pureza e ter na sua composição química $87 \%$ de portlandita $\left(\mathrm{Ca}(\mathrm{OH})_{2}\right), 11 \%$ de calcita $\left(\mathrm{CaCO}_{3}\right)$ e $2 \%$ de água e de $\mathrm{CO}_{2}$.

O material alternativo utilizado foi o resíduo da mineração da scheelita cedido pela Mina Brejuí, localizada no município de Currais Novos, Rio Grande do Norte. Esse foi utilizado em substituição total ao agregado natural e recebeu a denominação de areia de scheelita (AS). As argamassas estudadas nesta pesquisa foram confeccionadas nos traços em massa 1:3 (cimento: 100\% AS) e 1:1:6 (cimento: cal: 100\% AS). Essas condições de substituição e de escolha

Tabela 1 - Composição química do cimento Portland.

\begin{tabular}{|c|c|c|c|c|c|c|c|c|c|c|c|c|}
\hline Determinação & $\mathrm{CaO}$ & $\mathrm{SiO}_{2}$ & $\mathrm{MgO}$ & $\mathrm{Al}_{2} \mathrm{O}_{3}$ & $\mathrm{Fe}_{2} \mathrm{O}_{3}$ & $\mathrm{SO}_{3}$ & $\mathrm{~K}_{2} \mathrm{O}$ & $\mathrm{TiO}_{2}$ & $\mathrm{P}_{2} \mathrm{O}_{5}$ & OO & PF & $\mathrm{C}_{3} \mathrm{~A}$ \\
\hline Teor (\%) & 61,35 & 19,1 & 1,33 & 5,33 & 4,1 & 4,87 & 1,04 & 0,5 & 0,0 & 0,0 & 2,2 & 7,18 \\
\hline
\end{tabular}

OO: outros óxidos; PF: perda ao fogo; $\% \mathrm{C}_{3} \mathrm{~A}=2,650\left(\% \mathrm{Al}_{2} \mathrm{O}_{3}\right)-1,692\left(\% \mathrm{Fe}_{2} \mathrm{O}_{3}\right)$.

Fonte: elaborada pelos autores (resultado da análise em laboratório). 
dos traços foram estabelecidas conforme a comprovação da viabilidade técnica da substituição total do agregado natural pelo oriundo dos resíduos da mineração da scheelita realizada por Medeiros (2016) quanto à resistência à compressão simples.

\section{Métodos}

\section{Caracterização física, química e mineralógica da areia de scheelita}

A caracterização física do agregado estudado foi realizada com a determinação dos seguintes parâmetros: análise granulométrica por peneiramento, massa unitária e teor de material pulverulento. O peneiramento ocorreu utilizando a série normal de peneiras, seguindo os procedimentos da NBR NM 248 (ABNT, 2003). A composição química foi obtida por meio da espectrometria de fluorescência de raios X (FRX), usando o modelo Shimadzu EDX-720. A caracterização mineralógica foi realizada utilizando o difratômetro Shimadzu XRD-6000 com radiação $\mathrm{CuK \alpha} \alpha$, tensão de $40 \mathrm{kV}$, corrente de $30 \mathrm{~mA}$, modo de escaneamento por passos (fixed time scan), com passo de 0,02 e tempo de contagem de 0,6 s, com ângulo de varredura $2 \theta$ entre 5 e $60^{\circ}$.

\section{Determinação da variação dimensional de barras de argamassa expostas à solução de sulfato de sódio}

A ocorrência do ataque por sulfato nas amostras de argamassas confeccionadas com resíduos da mineração de scheelita em substituição total ao agregado natural foi avaliada pela sua variação dimensional quando imersas em solução de sulfato de sódio, conforme metodologia sugerida pela norma ABNT NBR 13583 (ABNT, 2014).

A quantidade de água para cada traço foi determinada pelo teste "flow table", em conformidade com a ABNT NBR 13276 (ABNT, 2002), a fim de garantir a trabalhabilidade adequada à argamassa, adotando-se o espalhamento padrão de 260 $\pm 10 \mathrm{~mm}$. Após a definição da quantidade de água, foram moldados seis corpos de prova prismáticos com dimensões de $25 \mathrm{~mm} \times 25 \mathrm{~mm} \times 285 \mathrm{~mm}$ para cada traço, os quais foram submetidos a um período de cura de 28 dias em câmara úmida com 100\% de umidade relativa (SHUQIANG, 2014) - o tempo de cura de 28 dias permite um aumento na resistência da argamassa em relação ao ataque de íons sulfato em razão da redução de $\mathrm{Ca}(\mathrm{OH})_{2}$. Após o período de cura, três corpos de prova foram imersos em água destilada e três em solução de sulfato de sódio por 42 dias. A expansão resultante da amostra, em porcentagem, foi determinada após sete, 14, 28 e 42 dias de imersão por meio de relógio comparador de expansibilidade digital, conforme determinado pela norma ABNT NBR 13583 (ABNT, 2014). O relógio comparador digital utilizado na pesquisa foi o modelo Digital ABSOLUTE 12,7mm 0,01mm ID-CX, da marca Mitutoyo.

\section{Análise estatística da expansão obtida após ataque por sulfato de sódio}

Neste estudo, foi realizada uma análise de regressão nos dados obtidos por meio do ensaio Cimento Portland - Determinação da variação dimensional de barras de argamassa de cimento Portland expostas à solução de sulfato de sódio, com o intuito de observar o comportamento da variação dimensional das barras de argamassa confeccionadas nos traços em massa 1:3 (cimento: $100 \%$ AS) e 1:1:6 (cimento: cal: 100\% AS). A escolha dessa análise estatística dos dados decorreu porque a expansão ou a retração que pode ocorrer nas barras de argamassas expostas ao ataque se correlaciona com o tempo, em dias, de imersão delas na solução saturada com sulfato de sódio, pois se trata de um ensaio acelerado. Todas as análises foram realizadas pelo software Excel.

\section{Degradação das argamassas submetidas ao ataque por sulfato de sódio}

A avaliação da degradação das argamassas estudadas por sulfato de sódio ocorreu utilizando como parâmetro a resistência à compressão simples (RCS) obtida para os corpos de prova atacados em solução de sulfato de sódio e os que ficaram submersos em água destilada, conforme metodologia proposta por Barros et al. (2019). Para determinar a RCS, moldou-se seis corpos de prova cilíndricos com dimensões de $50 \mathrm{~mm} \times 100 \mathrm{~mm}$ para cada traço em massa: 1:3 (cimento: 100\% AS) e 1:1:6 (cimento: cal: 100\% AS), curados por 28 dias em câmara úmida com $100 \%$ de umidade relativa. Logo, essa etapa complementa a verificação da reatividade do agregado oriundo do resíduo da mineração da scheelita à medida que os corpos de prova cilíndricos foram submetidos às mesmas condições dos prismáticos.

Após o período de cura, foram imersos três corpos de prova em água e três em solução de sulfato de sódio por 42 dias, e suas RCS foram determinadas de acordo com a norma ASTM C 780 (ASTM, 2006). Os ensaios para determinação da RCS foram executados em uma Máquina Universal Emic SSH300, célula Trd 30, com velocidade de carga de $0,25 \pm 0,05 \mathrm{Mpa} / \mathrm{s}$ e tratamento estatístico imposto pela NBR 7215 (ABNT, 1996).

\section{RESULTADOS E DISCUSSÃO}

\section{Caracterização física, química e mineralógica da areia de scheelita}

A Tabela 2 apresenta as propriedades físicas determinadas para a AS. A massa unitária foi de $1,69 \mathrm{~g} / \mathrm{cm}^{3}$, sendo categorizada como agregado normal, conforme classificação proposta por Bauer (1994), pois o valor da massa unitária apresentada por esse resíduo se encontra na faixa de valor $1 \leq \mathrm{y} \leq 2 \mathrm{~g} / \mathrm{cm}^{3}$. Logo, pode ser usado em argamassas.

$\mathrm{O}$ teor de materiais pulverulentos encontrado nesta pesquisa foi de $1,4 \%$ (Tabela 2), que é um valor baixo. Logo, segundo Bauer (1994) e Barros et al. (2017), pode-se afirmar que a AS apresentou poucos finos, o que a torna propícia ao uso em argamassas, pois demanda menor quantidade de água para o amassamento - o aumento do consumo de água provocaria retração e perda da resistência dessas argamassas. Com relação ao módulo de finura $(2,4 \%)$, o agregado estudado foi classificado como areia de granulometria média, segundo a NBR 7211 (ABNT, 1982).

Tabela 2 - Propriedades físicas da areia de scheelita.

\begin{tabular}{|c|c|c|}
\hline \multicolumn{2}{|l|}{ Ensaio } & AS \\
\hline \multicolumn{2}{|c|}{ Massa unitária ou aparente $\left(\mathrm{g} / \mathrm{cm}^{3}\right)$} & 1,69 \\
\hline \multicolumn{2}{|c|}{ Teor de materiais pulverulentos (\%) } & 1,4 \\
\hline \multirow{2}{*}{ Granulometria } & Diâmetro máximo & $2,37 \mathrm{~mm}$ \\
\hline & Módulo de finura (\%) & 2,4 \\
\hline
\end{tabular}

AS: areia de scheelita

Fonte: elaborada pelos autores (resultado da análise em laboratório) 
A Figura 1 apresenta a curva granulométrica da AS. De acordo com o comportamento dessa curva, constatou-se que a AS tem granulometria contínua e grãos mistos, uma característica que, segundo Bauer (1994), proporciona maior compacidade às argamassas.

A composição química da AS é apresentada na Tabela 3. A As apresentou valores elevados de óxido de cálcio $(\mathrm{CaO})$ e sílica $\left(\mathrm{SiO}_{2}\right)$. Observou-se também a presença de óxido de ferro e óxido de alumínio na amostra. O teor de alumina sugere a necessidade de se verificar a ocorrência do ataque por sulfato de sódio quando se usa AS em matrizes cimentícias (BARROS et al., 2017).

O difratograma de raio X da amostra AS está ilustrado na Figura 2. Observaram-se as seguintes fases mineralógicas: quartzo ( $\mathrm{SiO}_{2}$, JCPDS 46-1045), mica $\left(\mathrm{K}(\mathrm{Mg}, \mathrm{Fe})_{3}\left(\mathrm{Si}_{3} \mathrm{Al}\right) \mathrm{O} 10(\mathrm{OH})_{2}\right.$, JCPDS 83-1808) e calcita $\left(\mathrm{CaCO}_{3}\right.$, JCPDS 05-0586). O resultado do difratograma corrobora com a composição química da AS (Tabela 3). A reflexão principal estreita e alongada situada em $27,5<\theta<30^{\circ}$ é referente ao carbonato de cálcio, justificando o teor de óxido de cálcio e a perda ao fogo elevados na amostra. O teor de sílica na AS pode ser associado à presença da fase cristalina quartzo. Os teores de ferro e alumínio próximos de $10 \%$ estão relacionados com a presença da mica biotita, observado na reflexão entre 7,5< $\theta<10^{\circ}$. Os demais óxidos estão presentes como minerais acessórios (RAMOS et al., 2019). Resultados similares foram obtidos por Linhares e Silva (2014).

\section{Variação dimensional das barras de argamassas confeccionadas com areia de scheelita em substituição total ao agregado convencional}

As Figuras 3A e 3B ilustram as curvas das expansões obtidas pelas argamassas confeccionadas com AS após serem submetidas ao ataque por sulfato de sódio ao longo dos 42 dias.

O valor obtido para a expansão da argamassa de cimento Portland incorporada com AS no traço 1:3 aos 42 dias de exposição ao ataque por sulfato de sódio foi $0,083 \%$. Logo, esse valor evidencia que a argamassa estudada foi reativa

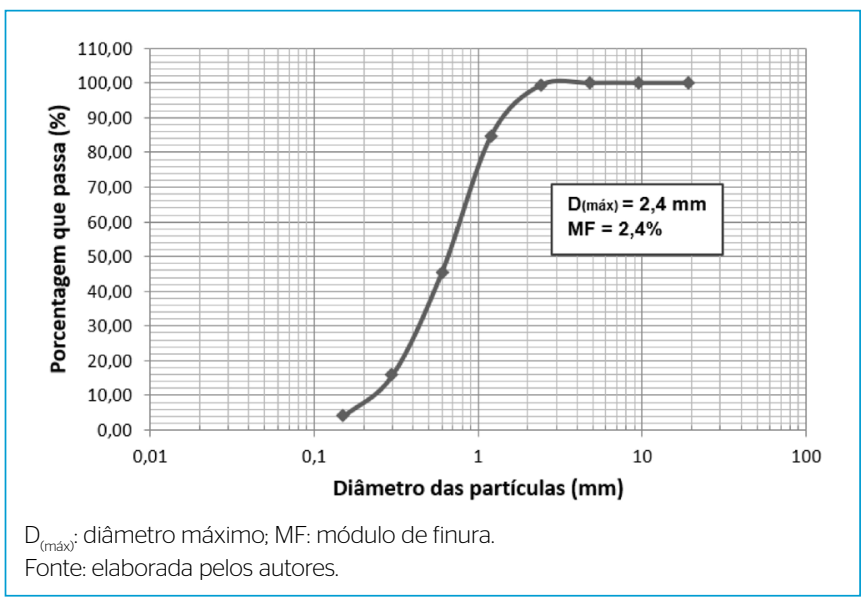

Figura 1 - Curva granulométrica da areia de scheelita. ao ataque por sulfato de sódio quando o método de avaliação aplicado foi a variação dimensional de barras de argamassas imersas em solução de sulfato de sódio, desde que o valor obtido se apresentasse acima da expansão estabelecida pela norma ASTM C 452 (ASTM, 2002).

Já a argamassa incorporada com AS no traço 1:1:6 apresentou aos 28 dias uma expansão de 0,078\%; nos dias seguintes sofreu uma retração, que fez com que a expansão obtida aos 42 dias de exposição ao ataque por sulfato de sódio caísse para $0,0575 \%$. Desse modo, esse traço permaneceu dentro do limite da expansão estabelecido pela norma ASTM C 452 (ASTM, 2002). Comportamento esse que pode ser condicionado à presença da cal na matriz cimentícia

As expansões ocorreram, possivelmente, em razão de a alumina presente no agregado (Tabela 3) reagir com o sulfato do cimento (Tabela 1), formando a etringita tardia. Conforme afirmam Merida et al. (2015), quando essa reação acontece, pode-se afirmar que os agregados são reativos com os íons sulfato, ocasionando expansões ou retrações. Estas não afetarão o comportamento do material se ficarem dentro do limite estabelecido pela norma, pois se trata de um ensaio acelerado.

\section{Análise de regressão da variação dimensional das barras de argamassas confeccionadas com areia de scheelita em substituição total ao agregado convencional}

Com a análise de regressão da variação das barras de argamassas para os intervalos de zero, sete, 14, 28 e 42 dias, confeccionadas com areia de scheelita em substituição total ao agregado convencional, obtiveram-se as curvas de regressão (Figura 4A e 4B) para as médias de três repetições. As equações 1 (traço 1:3) e 2 (traço 1:1:6) descrevem o comportamento das variações dimensionais ocorridas

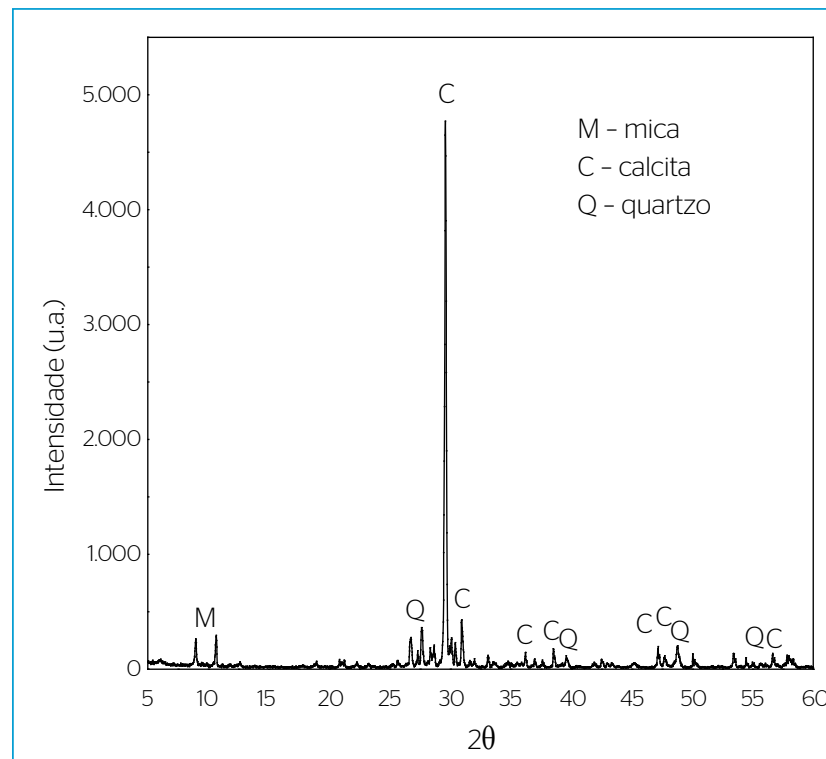

Fonte: elaborada pelos autores

Figura 2 - Difratograma de raio $\mathrm{X}$ da areia de scheelita.

Tabela 3 - Composição química da areia de scheelita.

\begin{tabular}{|c|c|c|c|c|c|c|c|c|c|}
\hline Amostra & PF (\%) & $\mathrm{CaO}(\%)$ & $\mathrm{SiO}_{2}(\%)$ & $\mathrm{Fe}_{2} \mathrm{O}_{3}(\%)$ & $\mathrm{Al}_{2} \mathrm{O}_{3}(\%)$ & $\mathrm{MgO}(\%)$ & $\mathrm{TiO}_{2}(\%)$ & $\mathrm{K}_{2} \mathrm{O}(\%)$ & Outros (\%) \\
\hline AS & 15,74 & 38,46 & 21,76 & 9,81 & 7,62 & 3,33 & 0,68 & 0,55 & 2,05 \\
\hline
\end{tabular}

PF: perda ao fogo

Fonte: elaborada pelos autores (resultado da análise em laboratório) 
A

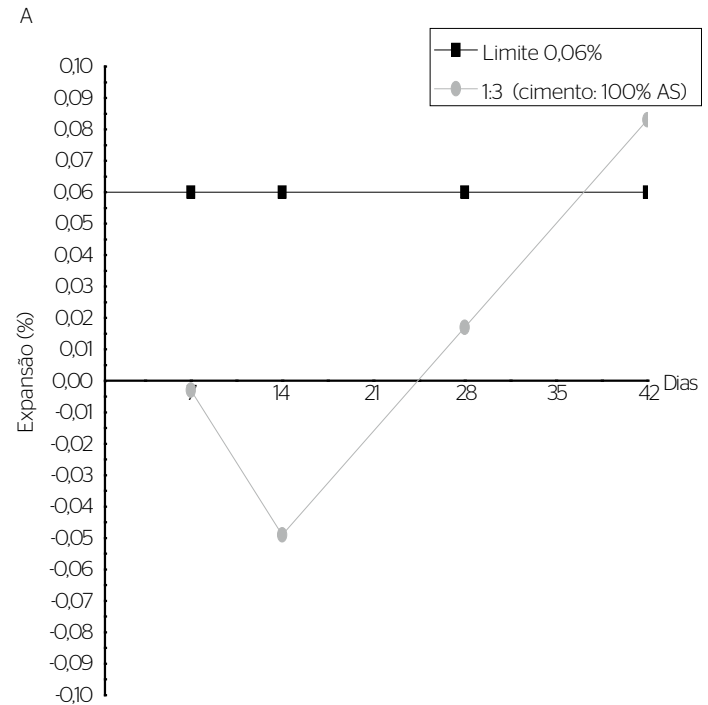

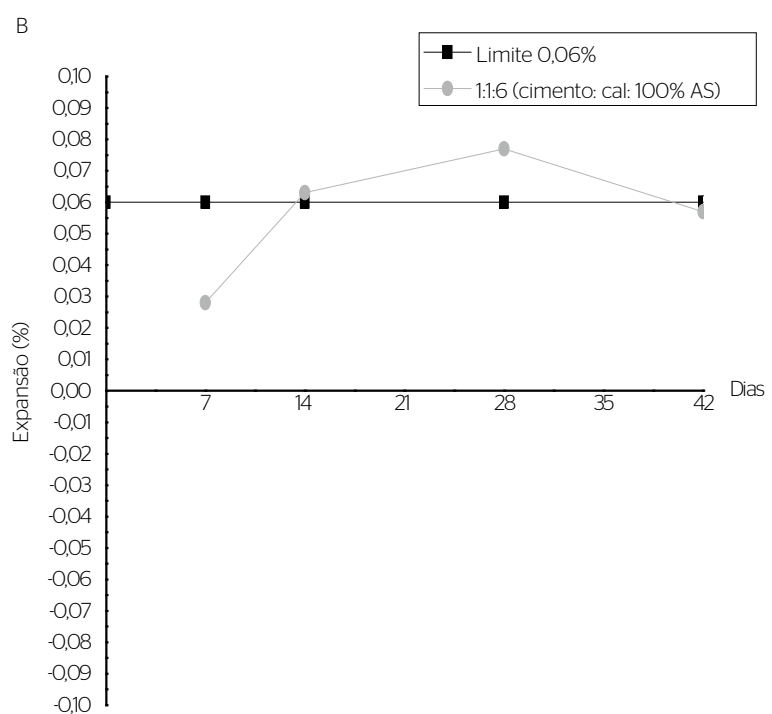

AS: areia de scheelita.

Fonte: elaborada pelos autores.

Figura 3 - Expansões dimensionais ao longo dos 42 dias de imersão em solução de sulfato de sódio. (A) Expansão para o traço 1:3 com 100\% de areia de scheelita e (B) expansão para o traço 1:1:6 com 100\% de areia de scheelita.

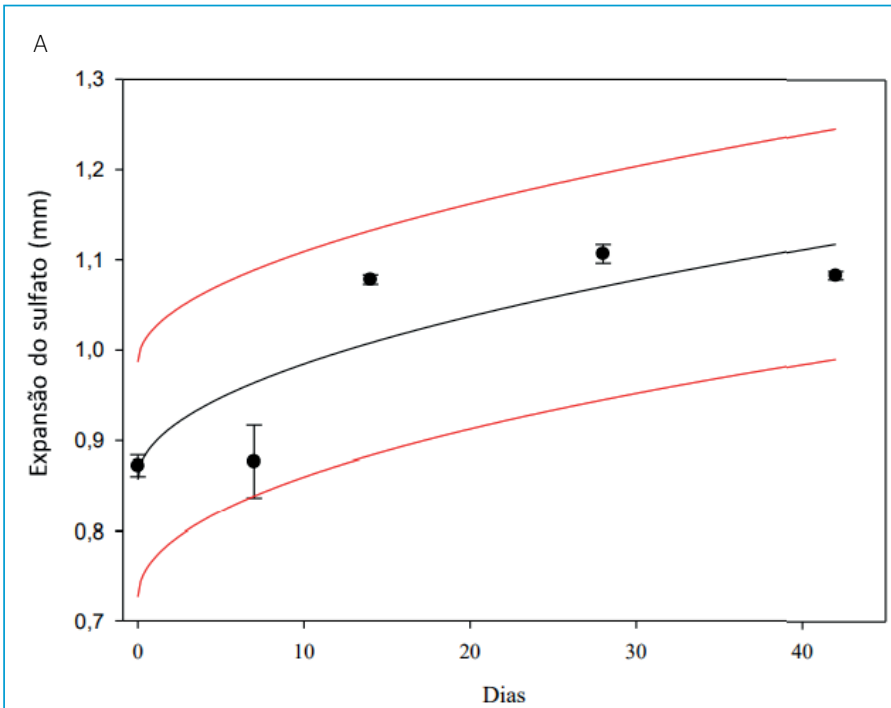

Fonte: elaborada pelos autores.

Figura 4 - Análise de regressão dos valores médios da variação da expansão do sulfato $(\mathrm{mm})$ com intervalo de confiança de $95 \%$ com suas respectivas barras de erro. (A) Regressão no traço 1:3 e (B) regressão no traço 1:1:6.

para as barras confeccionadas nos traços estudados; as linhas vermelhas indicam o intervalo de confiança de $95 \%$ (IC95\%) da predição dos valores calculados pelas equações de regressão.

As Equações de regressão 1 e 2 demonstraram que as variações das barras de argamassas estudadas, após serem atacadas por 42 dias por sulfato de sódio, foram significativas ao nível de $5 \%$ pelo teste $\mathrm{F}$, com valores de $\mathrm{R}^{2}=$ 0,95 e $\mathrm{R}^{2}=0,73$, respectivamente. Além disso, todos os pontos encontram-se dentro do IC95\% da predição dos modelos de regressão - como se esperava,

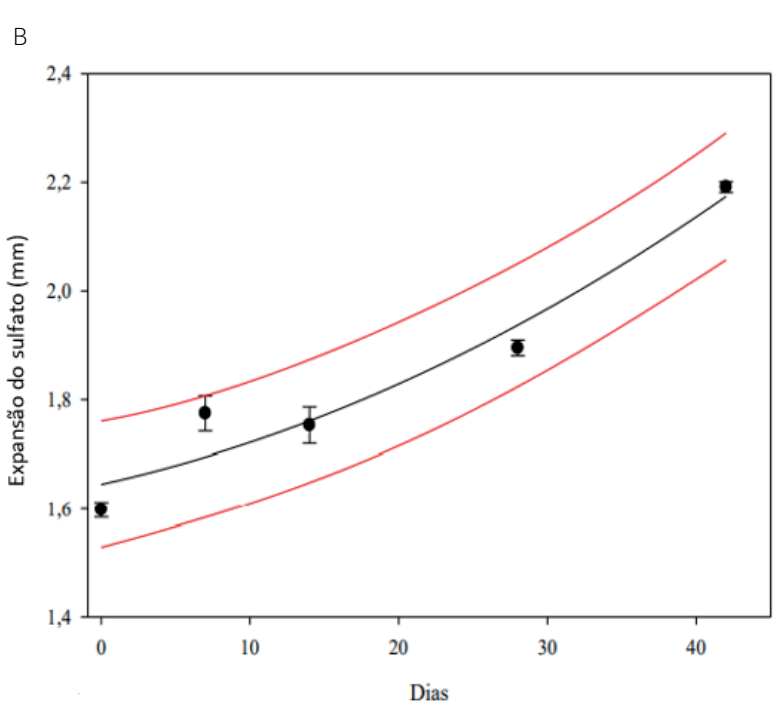

pois se trata de um ensaio acelerado por colocar o material investigado em uma solução saturada com os íons de sulfato de sódio, ou seja, cria-se um ambiente agressivo capaz de desencadear as reações caso o material seja reativo com os íons de sulfato.

$y=0,0002 x^{2}+0,005 x+1,646$

$y=0,8573+0,04 \sqrt{ } x$ 


\section{Degradação das barras de argamassas confeccionadas com areia de scheelita em substituição total ao agregado convencional após ataque por sulfato de sódio}

A Tabela 4 apresenta os valores obtidos para resistência à compressão simples dos corpos de prova após imersão em água destilada (42 dias) e em solução de sulfato de sódio (42 dias).

Os resultados apresentados na Tabela 4 indicaram que não ocorreu perda da RCS ao se comparar os valores da RCS obtidos após imersão em água destilada e solução de sulfato de sódio por 42 dias para as argamassas estudadas. Então, conforme esse parâmetro, verificou-se que não ocorreu a degradação mecânica dos corpos de prova para o período analisado, apesar de terem apresentado expansões características de argamassas não resistentes ao ataque por sulfatos. Provavelmente, de acordo com Barros et al. (2019), a desagregação não ocorreu porque o cimento apresenta teor de $_{3} \mathrm{~A}$ abaixo de $8 \%$ e, conforme a NBR 5737 (ABNT, 1992), o cimento apresenta certo grau de resistência ao ataque por sulfatos.

De acordo com Barros et al. (2019), as argamassas de cimento Portland que apresentam a formação de etringita e nas quais não ocorre fissuração e perda de RCS são explicadas pela quantidade de etringita tardia formada não ter sido suficiente para exceder um limiar capaz de gerar tensões sobre os sólidos vizinhos. Em relação às argamassas confeccionadas com AS estudadas neste trabalho, observou-se que essas argamassas são mais compactas e com menor quantidade de poros em relação à granulometria contínua da AS. Logo, pressupõe-se que impediu as movimentações abruptas da estrutura em razão da formação de etringita tardia (MEHTA \& MONTEIRO, 2008).

Tabela 4 - Valor médio da resistência à compressão simples dos corpos de prova após 42 dias de imersão.

\begin{tabular}{l|c|c|c|c} 
Traço & $\begin{array}{c}\text { RCS após 42 dias } \\
\text { de imersão em } \\
\text { água destilada } \\
\text { (Mpa) }\end{array}$ & $\begin{array}{c}\text { Desvio } \\
\text { padrão }\end{array}$ & $\begin{array}{c}\text { RCS após 42 dias } \\
\text { de imersão em } \\
\text { solução de sulfato } \\
\text { de sódio (Mpa) }\end{array}$ & $\begin{array}{c}\text { Desvio } \\
\text { padrão }\end{array}$ \\
$\begin{array}{l}1: 3 \text { (cimento: } \\
\text { 100\% AS) }\end{array}$ & 15,46 & $\pm 0,18$ & 16,23 & $\pm 0,66$ \\
\hline $\begin{array}{l}1: 1: 6 \text { (cimento: } \\
\text { cal: } 100 \% \text { AS) }\end{array}$ & 3,16 & $\pm 0,07$ & 4,86 & $\pm 0,40$ \\
\hline
\end{tabular}

RCS: resistência à compressão simples; AS: areia de scheelita.

Fonte: elaborada pelos autores.

\section{CONCLUSÃO}

Após estudos da variação dimensional das barras de argamassas incorporadas com a AS em substituição total ao agregado convencional, pode-se concluir que:

- A AS foi categorizada como agregado normal, com granulometria e teor de material pulverulento favoráveis ao uso em argamassas, sendo classificada, de acordo com a NBR 7211, em areia média, que proporcionou maior compacidade às argamassas estudadas.

- A composição química-mineralógica da AS indicou uma provável reatividade dessa areia com o sulfato de sódio em razão da presença da alumina (7,62\%), que foi confirmada com os resultados obtidos no ensaio da variação dimensional das argamassas submetidas ao ataque por sulfato de sódio. A AS reagiu com os íons de sulfato de sódio gerando expansões que ultrapassaram o limite estabelecido pela ASTM C 452 (0,06\%).

- O traço 1:1:6 apresentou um comportamento de expansão (0,078\%) aos 28 dias, que caracteriza o ataque. Porém, logo após, começa a sofrer retração, que leva a um valor de $0,0575 \%$ aos 42 dias - valor dentro do limite estabelecido pela ASTM C 452. Esse fato foi atribuído à adição de cal na argamassa.

- A degradação das argamassas estudadas não ocorreu. Tal fato foi constatado, provavelmente, porque o cimento Portland utilizado apresentou baixo teor de aluminato tricálcico e a granulometria da AS permitiu obter argamassas mais compactas, reduzindo assim a quantidade de material expansivo formado.

Diante dos resultados apresentados, conclui-se que o agregado oriundo dos resíduos gerados na extração da scheelita para ser utilizado na confecção de argamassas, considerando a durabilidade e a prevenção ao ataque químico por sulfato em regiões suscetíveis a esses, deve ocorrer fazendo uso de cimento resistente a sulfatos.

\section{CONTRIBUIÇÃO DOS AUTORES}

França Neta, M. L. X.: conceituação, curadoria de dados, análise formal, metodologia, escrita - primeira redação. Barros, S. V. V.: conceituação, curadoria de dados, metodologia, obtenção de financiamento. Neves, G. A.: curadoria de dados, metodologia. Silva, W. G.: curadoria de dados, metodologia, supervisão. Dantas, G. C. B: escrita - revisão e edição. Melo, S. B.: conceituação, análise formal, supervisão.

\section{REFERÊNCIAS}

ALVES, B. S.; PEREIRA, D. D.; IZIDIO JÚNIOR, L. R.; GURGEL, M. T. Análise comparativa o agregado miúdo com o rejeito da scheelita para aplicação na construção civil. In: $22^{\circ}$ Congresso Brasileiro de Engenharia e Ciência dos Materiais, 06 a 10 de novembro de2016, Natal-RN. Anais... Natal, RN, 2017.

AMERICAN SOCIETY FOR TESTING AND MATERIALS (ASTM). Standard Test Method for Potential Expansion of Portland-Cement Mortars Exposed to Sulfate. C 452, Pensilvânia, 2002.
AMERICAN SOCIETY FOR TESTING AND MATERIALS (ASTM). Standard Test Method for Preconstruction and Construction Evaluation of Mortars for Plain and Reinforced Unit Masonry. C 780, Pensilvânia, 2006.

ASSOCIAÇÃO BRASILEIRA DE NORMAS TÉCNICAS. Argamassa para assentamento e revestimento de paredes e tetos - Preparo da mistura e determinação do índice de consistência. Rio de Janeiro, NBR 13276. Rio de Janeiro: ABNT, 2002 
ASSOCIAÇÃO BRASILEIRA DE NORMAS TÉCNICAS. Cimento Portland Determinação da variação dimensional de barras de argamassa de cimento Portland expostas à solução de sulfato de sódio. NBR 13583. Rio de Janeiro: ABNT, 2014.

ASSOCIAÇÃO BRASILEIRA DE NORMAS TÉCNICAS. Agregados Determinação da composição granulométrica. NBR 248. Rio de Janeiro: ABNT, 2003.

ASSOCIAÇÃO BRASILEIRA DE NORMAS TÉCNICAS. Cimentos Portland resistentes a sulfatos. NBR 5737. Rio de Janeiro: ABNT, 1992

ASSOCIAÇÃO BRASILEIRA DE NORMAS TÉCNICAS. Cimentos Portland a Sulfato. NBR 5737. Rio de Janeiro: ABNT, 1992.

ASSOCIAÇÃO BRASILEIRA DE NORMAS TÉCNICAS. Cimentos Portland resistentes a sulfatos. NBR 5737. Rio de Janeiro: ABNT, 1992.

ASSOCIAÇÃO BRASILEIRA DE NORMAS TÉCNICAS. Agregados para concreto. NBR 7211. Rio de Janeiro: ABNT, 1982.

ASSOCIAÇÃO BRASILEIRA DE NORMAS TÉCNICAS. Cimento Portland Determinação da resistência à compressão. NBR 7215. Rio de Janeiro: ABNT, 1996.

ASSOCIAÇÃO BRASILEIRA DE NORMAS TÉCNICAS. Resíduos sólidos Classificação. NBR 10004. Rio de Janeiro: ABNT, 2004a.

BARROS, S. V. A.; NEVES, G. A.; MENEZES, R. R. Durabilidade de argamassas confeccionadas com resíduos de quartzito. 1.ed. Saoubrucken, Deutschland: Novas Edições Acadêmicas, 2017. 124 p.

BARROS, S. V. A.; NEVES, G. A.; MENEZES, R. R.; DANTAS, G. C. B.; PIMENTEL, P. M. Mechanical behavior and durability of mortars with quartzite and Portland cement after sulfate attack. Matéria, v. 24, n. 4, p. 1-9, 2019. https:// doi.org/10.1590/s1517-707620190004.0855

BAUER, L. A. F. Materiais de construção. 1. ed. São Paulo: LTC. Vol. 1,1994. 435 p.

BRASIL. Lei Federal $n^{\circ}$ 12305, de 2 de agosto de 2010. Institui a Política Nacional de Resíduos Sólidos; altera a Lei n9605, de 12 de fevereiro de 1998; e dá outras providências. Diário Oficial da União, Brasília, DF, 3 de agosto de 2010. Disponível em: http://www.mma.gov.br/port/conama/ legiabre.cfm?codlegi=636. Acesso em: 20 nov. 2019.

COSTA FILHOS, F. C. Estudo de viabilidade técnica do uso de resíduos oriundos do beneficiamento de scheelita na composição de concretos asfálticos. 148f. Dissertação (Mestrado em Engenharia Civil) - Universidade Federal do Rio Grande do Norte, Centro de Tecnologia, Programa de Pós-Graduação em Engenharia Civil. Natal, RN, 2017.

DANTAS, G. C. B.; FORBELONI, J. V.; PACHECO, A. S. V.; CAMPELO, I. C.; FARIAS, H. M. Perceptions of waste pickers in an association located in Seridó/RN about the adverse working conditions: an analysis of the collective subject. Revista Eletrônica em Gestão, Educação e Tecnologia Ambiental, v. 21, n. 3 , p. 210-221, 2017. https://doi.org/10.5902/2236117028013

ERCIKDI, B.; KULEKCI, G.; YILMAZ, T. Utilization of granulated marble wastes and waste bricks as mineral admixture in cemented paste backfill of sulphide-rich tailings. Construction and Building Materials, v. 93, p. 573-583, 2015. https://doi.org/10.1016/j.conbuildmat.2015.06.042

HOPPE FILHO, J.; SOUZA, D. J.; MEDEIROS, M. H. F.; PEREIRA, E.; PORTELLA, K. F. Ataque de matrizes cimentícias por sulfato de sódio: adições minerais como agentes mitigadores. Cerâmica, v. 61, n. 358, p. 168-177, 2015. https:// doi.org/10.1590/0366-69132015613581905

LINHARES, A. S.; SILVA, B. T. A. Aplicação do rejeito da scheelita em camadas granulares de pavimentos. In: XVII Congresso Brasileiro de Mecânica dos Solos e Engenharia Geotécnica, Goiânia, 09 de setembro de 2014. Anais do... Goiânia, 2014.

MEDEIROS, M. Estudo de argamassas de revestimento com resíduo de scheelita. 87 f. 2016. Dissertação (Mestrado em Engenharia Civil) - Centro de Tecnologia, Universidade Federal do Rio Grande do Norte, Natal, RN, 2016.

MEHTA, P. K.; MONTEIRO, P. J. M. Concreto: microestrutura, propriedades e materiais. 3. ed. São Paulo: IBRACON, 2008.

MERIDA, A.; KHARCHI, F. Pozzolan concrete durability on sulphate attack. Procedia Engineering, v. 114, 832-837, 2015. https://doi.org/10.1016/j. proeng.2015.08.035

MERSONI, C.; REICHERT, G. A. Comparação de cenários de tratamento de resíduos sólidos urbanos por meio da técnica da Avaliação do Ciclo de Vida: o caso do município de Garibaldi, RS. Engenharia Sanitária e Ambiental. v. 22, n. 5, p. 863-875, 2017. https://doi.org/10.1590/s1413-41522017150351

MOREIRA, M. S.; MANHÃES, J. P. V. T.; HOLANDA, J. N. F. Processing of red ceramic using ornamental rock powder waste. Journal of Materials Processing Technology, v. 196, p. 88-93, 2008. https://doi.org/10.1016/j. jmatprotec.2007.05.008

NEVILLE, A. M. Propriedades do Concreto. 5. Ed. Porto Alegre: Bookman, 1997. $828 \mathrm{p}$.

OUYANG, W. -Y; CHEN, J. -K.; JIANG, M. -Q. Q. Evolution of surface hardness of concrete under sulfate attack. Construction and Building Materials, v. 53 , p. 419-424, 2014. https://doi.org/10.1016/j.conbuildmat.2013.11.107

PAIVA, E. H. G. Avaliação do concreto de cimento Portland com resíduo da produção de scheelita em substituição ao agregado miúdo. 105 f. 2013. Dissertação (Mestrado em Engenharia Civil) - Universidade Federal do Rio Grande do Norte, Natal, RN, 2013

PIMENTEL, L. L.; PISSOLATO JÚNIOR, O.; JACINTHO, A. E. P. G. A.; MARTINS, H. L. S. Argamassa com areia proveniente da britagem de resíduo de construção civil - Avaliação de características físicas e mecânicas. Matéria, v. 23, n. 1, 2018. https://doi.org/10.1590/s1517-707620170001.0305

RAMOS, S. O.; DANTAS, G. C. B.; LIRA, H. L.; PIMENTEL, P. M.; MARCIANO, J. E. A. Caracterização de argilas de novos jazimentos situados em Parelhas/ RN, Brasil, visando aplicação na indústria cerâmica. Matéria, v. 24, n. 2, p. 1-9, 2019. https://doi.org/10.1590/s1517-707620190002.0667

RIBEIRO, V. A. S.; SILVA, A. L.; SILVA, M. R.; DIAS, J. C. Reciclagem de escória cristalizada para a produção de argamassa. Matéria, v. 12, n. 2, p. 339-345, 2007. https://doi.org/10.1590/s1517-70762007000200012

RIO GRANDE DO NORTE. Mutinacional quer pesquisar a existência de scheelita no RN. Secretaria do Desenvolvimento Econômico. 2016. Disponível em: http://www.consecti.org.br/giro-nos-estados/multinacionalquer-pesquisar-existencia-de-scheelita-no-rn/. Acesso em: 12 set. 2020.

ROZIËRE, E.; LOUKILI, A.; EL HACHEM, R.; GRONDIN, F. Durability of concrete exposed to leaching and external sulphate attacks. Cement and Concrete Research, v. 39, n. 12, p. 1188-1198, 2009. https://doi.org/10.1016/j. cemconres.2009.07.021 
SHUQIANG, X:; JULIN, W:; QINGLIN, M.; XIN, Z; TAO, Z. Study on the lightweight hydraulic lime and masonry waste as aggregate. Construction and Building Materials, v. 73, p. 33-40, 2014. https://doi.org/10.1016/j. conbuildmat.2014.09.062

SOUZA, D. J. Capacidade de adições minerais em mitigar o ataque por sulfatos de sódio e magnésio em argamassas de cimento Portland. 229 f. Dissertação (Mestrado em Engenharia de Construção Civil) - Universidade Federal do Paraná, Curitiba, PA, 2016. https://doi.org/10.4322/dissertation-2017.002
SHUQIANG, X.; JULIN, W.; QINGLIN, M.; XIN, Z.; TAO, Z. Study on the lightweight hydraulic lime and masonry waste as aggregate. Construction and Building Materials, v. 73, p. 33-40, 2014. https://doi.org/10.1016/j. conbuildmat.2014.09.062

SOUZA, D. J. Capacidade de adições minerais em mitigar o ataque por sulfatos de sódio e magnésio em argamassas de cimento Portland. $228 f$. Dissertação (Mestrado em Engenharia de Construção Civil) - Universidade Federal do Paraná, Curitiba, PA, 2016. 